\title{
FAKTOR-FAKTOR YANG MEMPENGARUHI MINAT PETANI DALAM BERUSAHATANI PADI DI KECAMATAN KEBAKKRAMAT KABUPATEN KARANGANYAR
}

\author{
Ardiyono Muhammad, Agustono, Arip Wijianto \\ Program Studi Agribisnis, Fakultas Pertanian, Universitas Sebelas Maret \\ E-mail: ardiyonomuhammad@gmail.com
}

\begin{abstract}
The research aims are (1) Analyse cost, revenue and income (2) Efficiency farming (3) Analyse the factors influencing interest farmers in the cultivation of rice in Kebakkramat district Karanganyar. The basic method of this research used the explanatory method. Research locations are Kebakkramat district Karanganyar. Method of the sample collection that is purposive sampling with the sample of the 60 farmers. The data used in this research are primary and secondary data. Methods of data analysis used in this research are (1) Analysis of cost, Revenue and Income (2) Efficiency Analysis (3) Binary Logistic Regression. The results showed that (1) Average cost of seeking Rp 4.457.348 per UT or Rp 9.682.870 per Ha, revenue of $R p$ 12.749.167 per UT or Rp 27.695.510 per Ha, earn an income of Rp 8.291.819 per UT or Rp 18.012 .641 per Ha (2) Farm efficiency of 2.89 (3) Variables influential real with an odd ratio: Variable commodity prices, variable price seed, variable the price of fertilizer and variable the availability of water. While variables which not influential real: Variable area of land, variable experience, variable age, variable education, variable government assistance, and variable alternation planting.
\end{abstract}

Keywords: Cost, Revenue, Income, Efficiency, Binary Logistic Regression

\begin{abstract}
Abstrak: Penelitian ini bertujuan untuk menganalisis (1) besarnya biaya, penerimaan dan pendapatan usahatani padi (2) Besarnya efisiensi usahatani padi (3) Faktor-faktor yang mempengaruhi minat petani dalam berusahatani padi di Kecamatan Kebakkramat Kabupaten Karanganyar. Metode dasar penelitian adalah explanatory. Lokasi penelitian yaitu Kecamatan Kebakkramat Kabupaten Karanganyar. Metode pengambilan sampel yaitu Purposive Sampling dengan jumlah sampel sebanyak 60 petani. Data yang digunakan dalam penelitian ini adalah data primer dan sekunder. Metode analisis data yang digunakan dalam penelitian ini adalah (1) Analisis biaya, Penerimaan dan Pendapatan (2) Analisis Efisiensi (3) Binary Logistic Regression. Hasil penelitian menunjukkan bahwa (1) Rata-rata biaya mengusahakan sebesar Rp 4.457.348 per UT atau Rp 9.682.870 per Ha, Penerimaan sebesar Rp 12.749.167 per UT atau Rp 27.695.510 per Ha, Pendapatan sebesar Rp 8.291.819 per UT atau Rp 18.012.641 per Ha (2) Nilai efisiensi adalah 2,89 (3) Variabel yang berpengaruh nyata dengan nilai $O d d$ Ratio yaitu: variabel harga komoditi, variabel harga benih, variabel harga pupuk dan variabel ketersediaan air. Sedangkan variabel yang tidak berpengaruh nyata yaitu: variabel luas lahan, variabel pengalaman, variabel umur, variabel pendidikan, variabel bantuan pemerintah, dan variabel pergiliran tanam.
\end{abstract}

Kata Kunci: Biaya, Penerimaan, Pendapatan, Efisiensi, Binary Logistic Regression

\section{PENDAHULUAN}

Pembangunan pertanian dikatakan sebagai pembangunan ekonomi di sektor pertanian, karena pertanian memang merupakan salah satu sektor dalam kehidupan ekonomi dan pengertian pertanian sendiri mengandung tekanan unsur ekonomi. Pertanian adalah usaha manusia dalam memenuhi kebutuhannya. Usaha manusia dalam sektor pertanian 
merupakan suatu usaha ekonomi ( Yuwono et all, 2011).

Pangan adalah sesuatu yang hakiki dan menjadi hak setiap warga negara untuk memperolehnya. Di Indonesia tanaman pangan penghasil karbohidrat yang digunakan oleh masyarakat masih terbatas pada beberapa jenis, yaitu padi, ubi kayu, dan ubi jalar (Purwono dan Purnamawati, 2007). Beras merupakan pangan penting dari berbagai jenis pangan karena peranannya menduduki struktur utama dalam konsumsi pangan masyarakat Indonesia. Beras juga merupakan makanan pokok lebiK dari 60 persen dari populasi dunia (Kolawole, 2006).

Sistem pembudidayaan tanaman padi di Indonesia secara garis besar dikelompokkan menjadi dua, yaitu padi sawah dan padi gogo (padi huma, padi ladang). Pada sistem sawah, tanaman padi sepanjang hidupnya selalu dalam keadaan tergenang air. (Purwono dan Purnamawati, 2007). Kegiatan yang dilakukan oleh petani di dalam usahatani, pada hakekatnya merupakan upaya memadukan yang saling mempengaruhi antara potensi sumberdaya (manusia) petani dengan sumbersumber produksi yang dapat dikuasai (Mardikanto, 2007). Minat adalah sebuah aspek yang menghubungkan antara seseorang dengan pekerjaan. Aspek tersebut merupakan suatu alasan mengapa para petani padi sawah masih tetap bertahan menjalankan usahatani.

Keputusan petani untuk memilih berusahatani padi atau tidak berusahatani padi tergantung pada minat petani itu sendiri. Petani memilih berusahatani padi dikarenakan beberapa faktor pendorong yang mempengaruhi minat petani untuk berusahatani padi. Wilayah Kabupaten Karanganyar yang memiliki produksi padi terbesar yaitu di Kecamatan Kebakkramat.

\section{METODE PENELITIAN}

Metode dasar yang digunakan dalam penelitian ini adalah explanatory dengan menggunakan pengambilan sampel secara purposive sampling pada bulan Mei-Agustus 2015. Data yang digunakan adalah data primer dengan 60 responden dan data sekunder sebagai pendukung.

Metode analisis yang digunakan adalah: (1) Analisis biaya, penerimaan dan pendapatan usahatani (2) Efisiensi usahatani (3) Binary Logistic Regression untuk mengetahui faktorfaktor yang mempengaruhi minat petani dalam berusahatani padi di Kecamatan Kebakkramat Kabupaten Karanganyar. Model persamaan dalam penelitian ini secara matematis dapat dituliskan sebagai berikut :

$\mathrm{Y}=\beta_{0}+\beta_{1} \mathrm{X}_{1}+\beta_{2} \mathrm{X}_{2}+\beta_{3} \mathrm{X}_{3}+\beta_{4} \mathrm{X}_{4}+\beta_{5} \mathrm{D}_{1}+$ $\beta_{6} D_{2}+\beta_{7} D_{3}+\beta_{8} D_{4}+\beta_{9} D_{5}+\beta_{10} D_{6}+\mu$

Keterangan: $\mathrm{Y}=$ Variabel dependen (Minat petani)

Dimana pada saat: $\mathrm{Y}=1$ menanam padi $\mathrm{Y}=0$ menanam selain padi atau bero

$\beta_{0}=$ Konstanta

$\beta_{1}-\beta_{10}=$ Koefisien Regresi

$\mathrm{X}_{1} \quad=$ Luas lahan

$\mathrm{X}_{2} \quad=$ Pengalaman

$\mathrm{X}_{3} \quad=$ Umur

$\mathrm{X}_{4} \quad=$ Pendidikan

$\mathrm{D}_{1}=$ Bantuan Pemerintah

Dimana pada saat:

$\mathrm{D}_{1}=1$ ada bantuan pemerintah

$\mathrm{D}_{1}=0$ tidak ada bantuan pemerintah

$\mathrm{D}_{2} \quad=$ Harga komoditi

Dimana pada saat:

$\mathrm{D}_{2}=1$ menarik

$\mathrm{D}_{2}=0$ tidak menarik

$\mathrm{D}_{3}=$ Harga benih

Dimana pada saat:

$\mathrm{D}_{3}=1$ menarik

$\mathrm{D}_{3}=0$ tidak menarik

$\mathrm{D}_{4}=$ Harga pupuk

Dimana pada saat:

$\mathrm{D}_{4}=1$ menarik

$\mathrm{D}_{4}=0$ tidak menarik

$\mathrm{D}_{5}=$ Ketersediaan air

Dimana pada saat:

$\mathrm{D}_{5}=1$ air tersedia

$\mathrm{D}_{5}=0$ air tidak tersedia

$\mathrm{D}_{6}=$ Pergiliran tanaman

Dimana pada saat:

$\mathrm{D}_{6}=1$ karena pergiliran tanaman

$\mathrm{D}_{6}=0$ tidak karena pergiliran tanaman

$\mu=$ Kesalahan Pengganggu 
Uji kelayakan model (Goodness of Fit), dilakukan Hosmer and Lameshow dengan pendekatan metode Chi square. Apabila nilai signifikansi di atas 0,10 maka model itu sudah memenuhi (fit).

Uji kelayakan secara keseluruhan (Overall Fit Test) dilakukan dengan omnibus test of model coefficient dengan pendekatan uji Chi square. Nilai signifikansi yang lebih kecil dari 0,10 maka keputusan minat petani berusahatani padi dapat diprediksi dari variabel bebas. Hal tersebut sejalan dengan Kolari (2000) bahwa model logit menghasilkan perkiraan koefisien untuk masing-masing variabel.

Uji secara parsial bertujuan menghubungkan 2 atau lebih variabel bebas dengan variabel terikat. Parameter yang digunakan adalah membandingan antara nilai signifikansi setiap variabel dengan taraf nyata 10\%. Apabila nilai signifikansi di bawah $10 \%$, maka variabel bebas tersebut berpengaruh signifikan terhadap variabel terikat.

Model regresi logistik melakukan interpretasi koefisien-koefisien dalam model melalui odd ratio (nilai kecenderungan). Rasio Odd ditulis sebagai B atau Exp (B). Rasio Odd digunakan untuk mengetahui kecenderungan peluang suatu variabel.

\section{HASIL DAN PEMBAHASAN}

\section{Kondisi Umum Lokasi Penelitian}

Kecamatan Kebakkramat terdiri dari 10 desa dengan luas wilayah 3.645,64 Ha. Kecamatan
Kebakkramat mempunyai ketinggian antara 0100 mdpl. Daerah ketinggian tersebut merupakan daerah pertanian yang baik terutama tanaman padi. Jumlah penduduk di Kecamatan Kebakkramat pada tahun 2014 tercatat sebesar 61.330 jiwa, terdiri dari 30.233 jiwa laki-laki dan 31.107 jiwa perempuan. Nilai ABT di Kecamatan Kebakkramat adalah sebesar 54,39\%. Hal ini berarti setiap 100 penduduk produktif harus menanggung 54 penduduk non produktif.

Kecamatan Kebakkramat memiliki luas panen padi terluas dibandingkan dengan tanaman pangan dan sayur-sayuran lainnya. Luas panen dan produksi padi yaitu 33.965 ton. Hal ini dikarenakan kondisi alam seperti topografi di Kecamatan Kebakkramat cocok untuk budidaya tanaman padi, juga dikarenakan adanya upaya pemerintah daerah dan para petani di Kecamatan Kebakkramat untuk lebih meningkatkan produksi padi agar ketersediaan bahan makanan berupa beras untuk penduduk Kabupaten Karanganyar tetap terjaga.

\section{Hasil dan Pembahasan \\ Biaya Usahatani \\ Biaya Alat-Alat Luar}

Berdasarkan Tabel 1 dapat diketahui rata-rata penggunaan sarana produksi terbesar menggunakan pupuk kandang yaitu 571,30 $\mathrm{kg} / \mathrm{UT}$ atau $1241,96 \mathrm{~kg} / \mathrm{UT}$. Penggunaan sarana produksi yang terkecil yaitu pupuk NPK sebesar $100,00 \mathrm{~kg} / \mathrm{UT}$ atau $217,39 \mathrm{~kg} / \mathrm{Ha}$.

Tabel 1. Rata-rata Penggunaan Sarana Produksi pada Usahatani Padi di Kecamatan Kebakkramat per Musim Kemarau (MT II)

\begin{tabular}{llrrr} 
No & $\begin{array}{l}\text { Biaya Sarana } \\
\text { Produksi }\end{array}$ & $\begin{array}{c}\text { Jumlah } \\
(\mathbf{k g} / \mathbf{U T})\end{array}$ & $\begin{array}{l}\text { Jumlah } \\
(\mathbf{k g} / \mathbf{H a})\end{array}$ & \multicolumn{2}{c}{ Harga Satuan (Rp) } \\
\hline 1. & Benih & 25,50 & 55,43 & 8.687 \\
2. & Pupuk & 571,30 & 1241,96 & 963 \\
& a. Kandang & 100,00 & 217,39 & 2.600 \\
& b. NPK & 110,34 & 239,87 & 1.946 \\
& c. Urea & 150,69 & 327,59 & 2.100 \\
d. Ponska & 116,92 & 254,17 & 1.933
\end{tabular}

Sumber: Analisis Data Primer 2016 
Tabel 2. Rata-rata Biaya Sarana Produksi pada Usahatani Padi di Kecamatan Kebakkramat per Musim Kemarau (MT II)

\begin{tabular}{llrr}
\hline No & Biaya Sarana Produksi & Per UT (Rp) & \multicolumn{1}{c}{ Per Ha (Rp) } \\
\hline 1. & Benih & 223.450 & 485.409 \\
2. & Pupuk & & \\
& a. Kandang & 419.567 & 911.442 \\
& b. NPK & 8.667 & 18.828 \\
& c. Urea & 202.700 & 440.333 \\
d. Ponska & 289.367 & 628.603 \\
& e. SP 36 & 186.833 & 405.865 \\
\hline Jumlah Rata-rata & $\mathbf{1 . 3 3 0 . 5 8 3}$ & $\mathbf{2 . 8 9 0 . 4 7 7}$ \\
\hline
\end{tabular}

Tabel 3. Rata-rata Biaya Tenaga Kerja Luar pada Usahatani Padi di Kecamatan Kebakkramat perMusim Kemarau (MT II)

\begin{tabular}{llrr}
\hline \multirow{2}{*}{ No } & & \multicolumn{2}{c}{ Tenaga kerja Luar } \\
\cline { 3 - 4 } & & \multicolumn{1}{c}{ Per UT (Rp) } & Per Ha (Rp) \\
\hline 1. & Persiapan Lahan & 780.000 & 1.694 .424 \\
2. & Pemupukan & 158.667 & 344.678 \\
3. & Menanam & 474.667 & 1.031 .138 \\
4. & Penyiangan & 420.000 & 912.382 \\
5. & Panen & 808.000 & 1.755 .250 \\
\hline & Jumlah & $\mathbf{2 . 6 4 1 . 3 3 3}$ & $\mathbf{5 . 7 3 7 . 8 7 0}$ \\
\hline
\end{tabular}

Sumber: Analisis Data Primer 2016

Tabel 4. Rata-rata Biaya Lain-lain pada Usahatani Padi di Kecamatan Kebakkramat per Musim Kemarau (MT II)

\begin{tabular}{llrr}
\hline No & Biaya Lain-lain & Per UT (Rp) & Per Ha (Rp) \\
\hline 1. & Biaya Penyusutan & & \\
& a. Cangkul & 2.239 & 4.864 \\
& b. Sabit & 2.739 & 5.950 \\
2. & Selamatan & 50.000 & 108.617 \\
3. & Iuran Air & 50.600 & 109.920 \\
4. & Transportasi & 150.000 & 325.851 \\
5. & Pajak Tanah & 15.837 & 34.403 \\
6. & Sewa Tanah & 40.000 & 86.894 \\
7. & Sewa Traktor & 236.667 & 514.121 \\
\hline & Jumlah & $\mathbf{3 0 3 . 4 3 1}$ & $\mathbf{6 5 9 . 1 5 5}$ \\
\hline
\end{tabular}

Sumber: Analisis Data Primer 2016

Berdasarkan Tabel 2, biaya sarana produksi total usahatani padi yang dikeluarkan dalam satu kali masa tanam adalah sebesar Rp. 1.330.583,00 per UT atau Rp. 2.890.477, 00 per Ha. Biaya sarana produksi terbesar yang digunakan dalam usahatani padi adalah biaya pembelian pupuk yaitu sebesar Rp. 1.107.133,00 per usahatani atau Rp. 2.405.070,00 per Hektar.

Berdasarkan Tabel 3, biaya tenaga kerja luar terbesar yang digunakan adalah biaya panen yaitu Rp 808.000,00 per UT atau Rp. 1.755.250,00 per Ha. Biaya tenaga kerja luar yang dikeluarkan dalam satu kali musim tanam kemarau adalah Rp 2.641.333,00 per usahatani atau Rp 5.737.870,00 per hektar.

Berdasarkan Tabel 4, biaya lain-lain terbesar adalah sewa traktor yaitu sebesar Rp 236.667,00 per UT atau Rp. 514.121,00 per Ha. Hal ini karena traktor merupakan alat yang dimiliki bersama dalam kelompok tani dan digunakan oleh banyak petani. Biaya perawatan traktor yang mahal memungkinkan untuk besarnya biaya sewa traktor. 
Tabel 5. Rata-rata Biaya Tenaga Kerja Keluarga pada Usahatani Padi di Kecamatan Kebakkramat per Musim Kemarau (MT II)

\begin{tabular}{llrr}
\hline \multirow{2}{*}{ No } & \multirow{2}{*}{ Biaya } & \multicolumn{2}{c}{ Tenaga Kerja Dalam } \\
\cline { 3 - 4 } & & Per UT $(\mathbf{R p})$ & \multicolumn{1}{c}{ Per Ha (Rp) } \\
\hline 1. & Persiapan Lahan & 29.333 & 63.721 \\
2. & Pemupukan & 61.333 & 133.236 \\
3. & Menanam & 23.333 & 50.687 \\
4. & Penyiangan & 42.000 & 91.238 \\
5. & Panen & 26.000 & 56.481 \\
\hline & Jumlah & $\mathbf{1 8 2 . 0 0 0}$ & $\mathbf{3 9 5 . 3 6 6}$ \\
\hline
\end{tabular}

Sumber: Analisis Data Primer 2016

Tabel 6. Biaya Mengusahakan pada Usahatani Padi di Kecamatan Kebakkramat per Musim Kemarau (MT II)

\begin{tabular}{llcc}
\hline No & Biaya Usahatani & Per UT $(\mathbf{R p})$ & Per Ha $(\mathbf{R p})$ \\
\hline 1. & Biaya Alat-Alat Luar & 4.275 .348 & 9.287 .504 \\
2. & Biaya Tenaga Kerja Keluarga & 182.000 & 395.366 \\
\hline & Jumlah & 4.457 .348 & 9.682 .870 \\
\hline
\end{tabular}

Sumber: Analisis Data Primer 2016

Tabel 7. Rata-rata Penerimaan Total Usahatani di Kecamatan Kebakkramat per Musim Kemarau (MT II)

\begin{tabular}{llrr}
\hline No & Keterangan & Per UT & \multicolumn{1}{c}{ Per Ha } \\
\hline 1. & Produksi $(\mathrm{Kg})$ & 3.579 & 7.775 \\
2. & Penerimaan $(\mathrm{Rp})$ & 12.749 .167 & 27.695 .510 \\
\hline
\end{tabular}

Sumber: Analisis Data Primer 2016

\section{Biaya Tenaga Kerja Keluarga}

Berdasarkan Tabel 5, biaya tenaga kerja keluarga terbesar yang digunakan dalam usahatani padi adalah biaya pemupukan yaitu sebesar Rp 61.333,00 per usahatani atau Rp. 133.236,00 per Hektar. Hal tersebut dikarenakan sebagian besar petani menggunakan tenaga kerja dalam keluarga untuk pemupukan tanaman padi dalam pembudidayaan.

Biaya Mengusahakan dalam usahatani padi adalah total dari semua biaya yang dikeluarkan oleh petani yang komponennya seperti dalam Tabel 6.

Berdasarkan Tabel 6 dapat diketahui bahwa penggunaan biaya terbesar dalam usahatani adalah biaya alat-alat luar sebesar $\mathrm{Rp}$ 4.275.348,00 per usahatani atau $\mathrm{Rp}$ 9.287.504,00 per hektar. Hal ini disebabkan biaya alat-alat luar meliputi biaya sarana produksi, biaya tenaga kerja luar dan biaya lain-lain. Biaya mengusahakan dalam usahatani padi sebesar Rp 4.457.348,00 per UT atau $\mathrm{Rp} 9.682 .870,00$ per Ha.

\section{Penerimaan Usahatani}

Penerimaan usahatani merupakan hasil perkalian dari produksi dengan harga per $\mathrm{Kg}$. Rincian penerimaan usahatani padi dapat dilihat pada Tabel 7.

Berdasarkan Tabel 7 dapat diketahui rata-rata produksi padi yang diperoleh petani adalah $3.579 \mathrm{~kg}$ per UT atau $7.775 \mathrm{~kg}$ per $\mathrm{Ha}$, rata-rata penerimaan yang diperoleh petani setelah panen adalah Rp. 12.749.167 per UT atau Rp. 27.695.510,00 per Ha. Adapun ratarata harga satuan per $\mathrm{kg}$ adalah $\mathrm{Rp} 3.560,00$.

\section{Pendapatan Usahatani}

Pendapatan usahatani padi diperoleh dari penerimaan dikurangi biaya. Rata-rata pendapatan usahatani padi dapat dilihat pada Tabel 8 . 
Ardiyono M., Agustono, Arip W. : Faktor-Faktor yang Mempengaruhi Minat Petani ...

Tabel 8. Rata-rata Pendapatan Usahatani di Kecamatan Kebakkramat per Musim Kemarau (MT II)

\begin{tabular}{llrr}
\hline No & Keterangan & Per UT & \multicolumn{1}{c}{ Per Ha } \\
\hline 1. & Penerimaan (Rp/UT) & 12.749 .167 & 27.695 .510 \\
2. & Biaya mengusahakan usahatani & 4.457 .348 & 9.682 .870 \\
& (Rp/UT) & & \\
3. & Pendapatan usahatani (Rp/UT) & $\mathbf{8 . 2 9 1 . 8 1 9}$ & $\mathbf{1 8 . 0 1 2 . 6 4 1}$ \\
\hline
\end{tabular}

Sumber: Analisis Data Primer 2016

Tabel 9. Efisiensi Usahatani Padi di Kecamatan Kebakkramat per Musim Kemarau (MT II)

\begin{tabular}{llrr}
\hline No & Uraian & Jumlah & R/C Ratio \\
\hline 1. & Penerimaan $(\mathrm{Rp} / \mathrm{Ha})$ & 27.695 .510 & \\
2. & Biaya mengusahakan usahatani & 9.682 .870 & \\
& $(\mathrm{Rp} / \mathrm{Ha})$ & & 2,89 \\
\hline
\end{tabular}

Sumber: Analisis Data Primer 2016

Tabel 10. Hosmer Lameshow test

\begin{tabular}{llll}
\hline Step & Chi-square & Df & Sig. \\
\hline 1 & 4.317 & 8 & .827 \\
\hline
\end{tabular}

Sumber: Data primer yang diolah, 2016

Tabel 11. Omnibus Tests of Model Coefficients

\begin{tabular}{llccc}
\hline & & Chi-square & Df & Sig. \\
\hline Step & Step & 41.400 & 10 & .000 \\
& Block & 41.400 & 10 & .000 \\
& Model & 41.400 & 10 & .000 \\
\hline
\end{tabular}

Sumber: Data primer yang diolah,2016

Berdasarkan Tabel 8, pendapatan usahatani padi sebesar Rp. 8.291.819,00 per UT atau Rp. 18.012.641,00 per Ha. Tabel 8 menunjukkan bahwa rata-rata petani tidak mengalami kerugian.

\section{Efisiensi Usahatani}

Menurut Khai (2011), pengukuran efisiensi dalam produksi pertanian menentukan tingkat efisiensi rumah tangga dalam kegiatan pertanian ( Khai, 2011). Efisiensi dapat dihitung dari perbandingan antara besar penerimaan dan biaya yang digunakan untuk berproduksi yaitu dengan menggunakan R/C Rasio. Besarnya efisiensi usahatani padi ditunjukkan pada Tabel 9. Berdasarkan Tabel 9, R/C Ratio padi sebesar 2,89. Hal ini berarti setiap satu rupiah biaya yang dikeluarkan akan menghasilkan penerimaan sebesar 2,89 rupiah. Nilai R/C Ratio (2,89>1) memberikan informasi bahwa usahatani yang dilakukan petani padi di Kecamatan Kebakkramat sudah efisien.

Analisis Binary Logistic Regression Uji Kelayakan Model (Goodness of Fit)

Berdasarkan Tabel 10, Hosmer Lameshow test menghasilkan nilai Chi square sebesar 4,317 dengan signifikansi sebesar 0,827 $(0,827>0,10)$, maka diperoleh adanya persamaan antara data estimasi model regresi logistik dengan data observasinya. Hal ini berarti bahwa model tersebut sudah memenuhi fit model

\section{Overall Fit Test}

Berdasarkan Tabel 11, Omnibus Tests of Model Coefficients menghasilkan nilai chi square sebesar 41,400 dengan signifikansi sebesar $0,000 \quad(0,000<0,10)$ memungkinkan diperoleh overall fit model. Sehingga model dengan sepuluh prediktor menunjukkan sebagai model yang baik. 


\section{Uji secara Parsial}

Tabel 12. Hasil uji Binary Logistic Regression

\begin{tabular}{lrrr}
\hline \multicolumn{1}{c}{ Variabel } & B & Sig. & Odd Ratio \\
\hline Luas Lahan $\left(\mathrm{X}_{1}\right)$ & $-2.226^{\mathrm{ns}}$ & .228 & .108 \\
Pengalaman $\left(\mathrm{X}_{2}\right)$ & $-.097^{\mathrm{ns}}$ & .165 & .908 \\
Umur $\left(\mathrm{X}_{3}\right)$ & $.124^{\mathrm{ns}}$ & .203 & 1.132 \\
Pendidikan $\left(\mathrm{X}_{4}\right)$ & $.341^{\mathrm{ns}}$ & .103 & 1.406 \\
Bantuan Pemerintah & $1.544^{\mathrm{ns}}$ & .111 & 4.682 \\
$\left(\mathrm{X}_{5}\right)$ & & & \\
Harga Komoditi $\left(\mathrm{X}_{6}\right)$ & $1.811^{*}$ & .074 & 6.119 \\
Harga Benih $\left(\mathrm{X}_{7}\right)$ & $1.918^{*}$ & .040 & 6.804 \\
Harga Pupuk $\left(\mathrm{X}_{8}\right)$ & $2.114^{*}$ & .091 & 8.281 \\
Ketersediaan air $\left(\mathrm{X}_{9}\right)$ & $1.544^{*}$ & .088 & 4.681 \\
Pergiliran Tanam & $-1.199^{\mathrm{ns}}$ & .235 & .302 \\
$\left(\mathrm{X}_{10}\right)$ & & & \\
Constant & -10.570 & .065 & .000 \\
\hline Suber: Data prim
\end{tabular}

Sumber: Data primer yang diolah, 2016

Keterangan:

* = Berpengaruh nyata pada tingkat signifikansi $10 \%$

$\mathrm{ns}=$ Tidak berpengaruh nyata

$$
\begin{gathered}
\mathrm{L}=\ln \frac{p}{(1-P)}=-10,750-2,226 \mathrm{X}_{1}-\quad 0,097 \mathrm{X}_{2}+0,124 \mathrm{X}_{3}+0,341 \mathrm{X}_{4}+ \\
1,544 \mathrm{X}_{5}+1,811 \mathrm{X}_{6}+1,918 \mathrm{X}_{7}+2, \quad 114 \mathrm{X}_{8}+1,544 \mathrm{X}_{9}-1,199 \mathrm{X}_{10}
\end{gathered}
$$

\section{Luas lahan $\left(\mathbf{X}_{1}\right)$}

Koefisien variabel luas lahan $\left(\mathrm{X}_{1}\right)$ sebesar 2,226 dan tingkat signifikan sebesar 0,228 $(0,228>0,10)$, maka dapat diartikan variabel luas lahan tidak berpengaruh nyata terhadap minat petani berusahatani padi.

\section{Pengalaman $\left(\mathbf{X}_{2}\right)$}

Koefisien variabel pengalaman $\left(\mathrm{X}_{2}\right)$ sebesar 0,097 dan tingkat signifikan sebesar 0,165 $(0,165>0,10)$, maka dapat diartikan variabel pengalaman tidak berpengaruh nyata terhadap minat petani berusahatani padi.

\section{$\operatorname{Umur}\left(\mathbf{X}_{\mathbf{3}}\right)$}

Koefisien variabel umur $\left(\mathrm{X}_{3}\right)$ sebesar 0,124 dan tingkat signifikan sebesar $0,203(0,203>0,10)$, maka dapat diartikan variabel umur tidak berpengaruh nyata terhadap minat petani berusahatani padi.

\section{Pendidikan $\left(\mathbf{X}_{4}\right)$}

Koefisien variabel pendidikan $\left(\mathrm{X}_{4}\right)$ sebesar 0,341 dan tingkat signifikan sebesar 0,103. $(0,103>0,10)$, maka dapat diartikan variabel pendidikan tidak berpengaruh nyata terhadap minat petani berusahatani padi.

\section{Bantuan pemerintah $\left(\mathrm{X}_{6}\right)$}

Koefisien variabel bantuan pemerintah $\left(\mathrm{X}_{6}\right)$ sebesar 1,544 dan tingkat signifikan sebesar $0,111(0,111>0,10)$, maka dapat diartikan variabel bantuan pemerintah tidak berpengaruh nyata terhadap minat petani berusahatani padi.

\section{Harga komoditi $\left(\mathbf{X}_{7}\right)$}

Koefisien variabel harga komoditi $\left(\mathrm{X}_{7}\right)$ sebesar 1,811 dan tingkat signifikansi sebesar 0,074 $(0,074<0,10)$, maka dapat diartikan variabel harga komoditi berpengaruh nyata positif terhadap minat petani berusahatani padi. Nilai Odd Ratio sebesar 6,119. Artinya kemungkinan setiap bertambah menariknya harga komoditi maka akan menaikkan minat petani untuk berusahatani padi di Kecamatan Kebakkramat Kabupaten Karanganyar sebesar 6,119 kali.

Harga komoditi dikatakan menarik jika harga komoditi tergolong mahal di pasaran. Harga komoditi yang mahal ditentukan dengan produk yang berkualitas. Kualitas yang baik dihasilkan oleh proses produksi yang dilakukan dengan baik (Soekartawi, 1995). Penjualan hasil produksi yang berkualitas akan memperoleh penerimaan yang tinggi. Sehingga petani akan termotivasi untuk menanam 
komoditi tersebut pada musim tanam selanjutnya. Sedangkan jika harga komoditi tidak menarik berarti harga komoditi tersebut rendah dipasaran. Petani akan memilih untuk berusahatani komoditi lain yang memiliki harga komoditi yang tinggi dipasaran.

\section{Harga benih $\left(\mathbf{X}_{7}\right)$}

Koefisien variabel harga benih $\left(\mathrm{X}_{7}\right)$ sebesar 1,918. dan tingkat signifikansi sebesar 0,040 $(0,040<0,10)$, maka dapat diartikan variabel harga benih berpengaruh nyata positif terhadap. Nilai Odd Ratio sebesar 6,804. Artinya kemungkinan setiap bertambah menariknya harga benih maka akan menaikkan minat petani untuk berusahatani padi di Kecamatan Kebakkramat Kabupaten Karanganyar sebesar 6,804 kali.

Harga benih dikatakan menarik jika harga benih tergolong murah. Penggunaan benih merupakan langkah awal yang ikut menentukan tinggi rendahnya produksi tanaman. Semakin baik mutu benih, produksi tanaman akan semakin tinggi (Samadi, 2003). Jika harga benih terlalu mahal, maka harga benih tersebut tidak menarik bagi petani. Dengan demikian, petani akan memilih benih lain yang lebih terjangkau dan masih dipercaya mampu untuk menghasilkan produk komoditi yang laku dipasaran.

\section{Harga pupuk $\left(\mathbf{X}_{8}\right)$}

Koefisien variabel harga pupuk $\left(\mathrm{X}_{8}\right)$ sebesar 2,114 dan tingkat signifikan sebesar 0,091 $(0,091<0,10)$, maka dapat diartikan variabel harga pupuk berpengaruh nyata positif terhadap minat petani berusahatani padi. Nilai Odd Ratio sebesar 8,281. Artinya kemungkinan setiap bertambah menariknya harga pupuk maka akan menaikkan minat petani untuk berusahatani padi di Kecamatan Kebakkramat Kabupaten Karanganyar sebesar 8,281 kali.

Harga pupuk dikatakan menarik jika harga pupuk tersebut tergolong murah dipasaran. Harga pupuk yang murah akan menarik perhatian petani untuk membelinya. Pemberian pupuk yang optimal dapat diberikan jika komposisi pupuk yang diperlukan tersedia bagi petani. Tersedianya pupuk ini tergantung pada harga pupuk yang berlaku dipasaran. Jika harga pupuk sangat tinggi, petani akan mempertimbangkan membeli pupuk tersebut sesuai kebutuhan atau meminimalisir penggunaan pupuk untuk usahataninya. Petani dalam berusahatani melakukan perbandingan antara hasil yang diharapkan dan yang akan diterima pada waktu panen dengan biaya yang harus dikeluarkan (Mubyarto, 1989). Semakin rendah biaya yang harus dikeluarkan daripada hasil yang akan diterima maka petani akan semakin puas.

\section{Ketersediaan air $\left(\mathbf{X}_{\mathbf{9}}\right)$}

Koefisien variabel ketersediaan air $\left(\mathrm{X}_{9}\right)$ sebesar 1,544 dan tingkat signifikan sebesar 0,088 $(0,088<0,10)$, maka dapat diartikan variabel ketersediaan air berpengaruh nyata positif terhadap minat petani berusahatani padi. Nilai Odd Ratio sebesar 4,681. Artinya kemungkinan setiap peningkatan ketersediaan air maka akan menambah minat petani untuk berusahatani padi di Kecamatan Kebakkramat Kabupaten Karanganyar sebesar 4,681 kali.

Air merupakan sumber kehidupan bagi makhluk hidup, termasuk juga tanaman seperti padi yang membutuhkan air untuk terus tumbuh. Jika ketersediaan air memadai, maka tanaman padi dapat terus tumbuh untuk berproduksi. Hal ini akan menguntungkan bagi petani yang membudidayakan tanaman padi. Sehingga petani padi akan berupaya memperoleh ketersediaan air yang cukup untuk membudidayakan tanaman padi. Jika ketersediaan air tidak mencukupi, petani akan membudidayakan komoditas lain yang membutuhkan sedikit air untuk tumbuh dan berproduksi.

\section{Pergiliran tanam $\left(\mathbf{X}_{10}\right)$}

Koefisien variabel pergiliran tanam $\left(\mathrm{X}_{10}\right)$ sebesar -1,199 dan tingkat signifikan sebesar $0,235(0,235>0,10)$, maka dapat diartikan variabel pergiliran tanam tidak berpengaruh nyata terhadap minat petani berusahatani padi.

\section{KESIMPULAN}

Berdasarkan hasil penelitian usahatani padi dan analisis menggunakan Binary Logistic Regression dapat disimpulkan biaya mengusahakan rata-rata yang dikeluarkan petani pada usahatani padi MT II (MeiAgustus) 2015 yaitu Rp 4.457.348 per UT atau Rp 9.682.870 per Ha. Rata-rata penerimaan total yang diterima petani padi adalah sebesar Rp 12.749.167 per UT atau Rp 27.695.510 per 
Ha. Rata-rata pendapatan yang diterima sebesar Rp 8.291.819 per UT atau Rp 18.012.641 per Ha. Efisiensi usahatani padi adalah 2,89 yang mengindikasikan bahwa usahatani padi yang dilakukan sudah efisien. Hasil estimasi yang diperoleh berdasarkan model analisis Binary Logistic Regression, dalam berusahatani padi minat petani dipengaruhi oleh nilai Odd Ratio oleh variabel harga komoditi $\left(\mathrm{X}_{6}\right)$, variabel harga benih $\left(\mathrm{X}_{7}\right)$, variabel harga pupuk $\left(\mathrm{X}_{8}\right)$, variabel ketersediaan air $\left(\mathrm{X}_{9}\right)$. Sedangkan variabel yang tidak berpengaruh nyata yaitu: variabel luas lahan $\left(\mathrm{X}_{1}\right)$, variabel pengalaman $\left(\mathrm{X}_{2}\right)$, umur $\left(\mathrm{X}_{3}\right)$, variabel pendidikan $\left(\mathrm{X}_{4}\right)$, variabel bantuan pemerintah $\left(\mathrm{X}_{5}\right)$, variabel pergiliran tanam $\left(\mathrm{X}_{10}\right)$. Usahatani padi yang dilakukan di Kecamatan Kebakkramat Kabupaten Karanganyar sudah efisien dengan melihat tingkat produktivitas dan pendapatan yang cukup tinggi, untuk itu saran yang dapat diberikan yaitu petani hendaknya berusaha untuk terus mengembangkan pertanian padi. Pengembangan tersebut dapat dilakukan, salah satunya dengan menggerakkan kelompok tani agar lebih aktif sehingga petani padi tidak ketinggalan informasi terbaru yang berkaitan dengan usahatani. Pemerintah diharapkan memberikan subsidi atau menurunkan harga benih dan harga pupuk yang tepat sasaran, memberikan standar harga komoditi yang jelas dipasaran sehingga tidak merugikan petani dalam menjual hasil produksi, memperbaiki sistem irigasi agar ketersediaan air dapat secara menyeluruh sampai ke setiap lahan usahatani. Model Binary Logistic Regression yang telah disusun diharapkan dapat membantu perencanaan pembangunan di bidang pertanian dalam memperkirakan jumlah petani yang berminat berusahatani padi. Hal ini dapat menjadi masukan bagi semua pihak yang ingin meneliti hal yang serupa, sehingga menambah ragam alat analisis. Model yang digunakan tersebut dapat menjelaskan minat petani berusahatani padi dan faktor-faktor yang mempengaruhinya di Kecamatan Kebakkramat Kabupaten Karanganyar.

\section{DAFTAR PUSTAKA}

Khai, H. V., Yabe, M. 2011. Technical Efficiency Analysis of Rice Production in Vietnam. J. ISSAAS, Vol. 17, No. 1:135-146.

Kolari, James. 2000. Predicting Large US Commercial Bank Failure. Journal of Economics and Business. Vol 54, No.4: 361-387

Kolawole O. 2006. Determinants of Profit Effciency Among Small Scale Rice Farmers in Nigeria: A Profit Function Approach. University of Delaware Press. Akure. https://www.researchgate.net. Diakses pada tanggal 16 Juni 2016.

Mardikanto, Totok. 2007. Pengantar Ilmu Pertanian: Untuk Mahasiswa dan Peminat Pertanian. Pusat Pengembangan Agrobisnis dan Perhutanan Sosial. Surakarta.

Mubyarto. 1989. Pengantar Ekonomi Pertanian. PT Intermasa. Jakarta.

Purwono dan Heni Purnamawati. 2007. Budidaya 8 Jenis Tanaman Pangan Unggul. Penebar Swadaya. Jakarta.

Samadi, Budi. 2003. Usaha Tani Kacang Panjang. Kanisius. Yogyakarta.

Soekartawi. 1995. Analisis Usahatani.UI Press. Jakarta.

Yuwono, Triwibowo et all. 2011. Pembangunan Pertanian: Membangun Kedaulatan Pangan. Gadjah Mada University Press. Yogyakarta 